\title{
Research on electric power development and economic growth in Hebei Province based on business cycle analysis
}

\author{
Miao Liang ${ }^{1}$, Meng Chen ${ }^{2 *}$, Yan $\mathrm{Li}^{3}, \mathrm{Xiaomin} \mathrm{Xu}^{2}$ and Dongxiao $\mathrm{Niu}^{2}$ \\ ${ }^{1}$ Electric Power Research Institute of State Grid Shaanxi Electric Power Company, Xi'an 710100, China; \\ ${ }^{2}$ School of Economics and Management, North China Electric Power University, Beijing 102206, China; \\ ${ }^{3}$ Electric Power Research Institute of State Grid Shandong Electric Power Company, Jinan 250021, China;
}

\begin{abstract}
With the improvement of China's electrification level, the relationship between electricity power consumption and social economy development is getting closer. Under this background, in this paper, the business cycle analysis method is applied to the electricity power industry in Hebei Province, and the link between electric power generation and economic development is determined through the prosperity index. First of all, the steps and methods of business cycle analysis were introduced, and the time-difference grey correlation method considering the consistency of time series to screen indicators was put forward, thus to reduce the number of indicators. Next, Hebei Province was taken as an example, and its monthly data related to power generation and economic growth in the 10 years from 2009 to 2018 to was selected to build the business cycle indicator system, at last the composite prosperity index of Hebei Province in electric power industry was calculated. This research results manifest that it is feasible to apply the business cycle analysis to the power industry.
\end{abstract}

\section{Introduction}

Electric power industry is the basic energy industry related to social and economic development, and its development status is closely related to the prosperity of economy. A large number of studies show that the electricity consumption trend is consistent with the economic expansion, recession, and recovery[1-3]. Therefore, it is of great importance to build a scientific prosperity index concerning both electricity power development and economic growth based on the relevant methods of business prosperity cycle, thus to examine the link between electric power industry and economy, and predict the trend of power and economic development.

At present, a large number of researches discuss and analyze the relationship between economic growth and power energy consumption with econometric method. For example, literature [4] used traditional methods and econometric tools to investigate the causal relationship between Poland's power consumption and GDP; literature [5] discussed the relationship between the change of macroeconomic conditions and electrical usage in the commercial and industrial sectors; literature [6] studied the key issues in the relationship between power consumption and economic growth. All these researches had laid a foundation for the application of business cycle analysis methods to the power industry.

Although current researches on the relationship between electricity consumption and economic growth is relatively sufficient, the relevant research on the application of business cycle analysis method in the field of electricity power industry is still rare [7-14]. At present, State Grid Corporation of China is trying to use electricity prosperity index to explore the law of electricity consumption to guide the development of enterprises [15, 16]. The main approach of SGCC is to use the whole society's electricity consumption as the reference indicator for analysis, classify the electricity consumption according to different industries, and use the time series of electricity consumption of each industry as the primary indicators for business cycle analysis, and then use the business cycle analysis method to screen the indicators consistent with the fluctuation trend of electricity consumption of the whole society as the final prosperity indicator for prosperity index calculation. As the power consumption of each industry is an integral part of the whole society's power consumption, the essence of this approach is to study the impact of the industry with a large proportion of power consumption on the overall power consumption, and it lacks of consideration of other factors affecting the power development.

The main purpose of this paper are as follows.

1. Applying the method of business cycle analysis to the electric power industry, using the time series of electric power industry and economic growth to calculate the prosperity index and establish the link between electric power and economic development

2. Studying the periodic changes of electric power supply and demand, exploring the fluctuation law in electric power development, thus to guide the development of all parties involved in electric power industry and formulate corresponding strategies.

\footnotetext{
" Corresponding author: ealinne13@ncepu.edu.cn
} 
The main innovations of this paper include:

1. It is proposed to apply the business cycle analysis method to the electric power industry to study the periodic change of electric power energy fluctuation and social economic development.

2. A new method of seasonal adjustment, realtime difference grey correlation method, is proposed to further reduce the number of time series.

\section{Methodology}

This section mainly introduces the division of prosperity indicators with the method called time-difference correlation analysis and the improved method called timedifference grey correlation.

The commonly methods for the division of prosperity indicators are mainly time-difference correlation analysis method and K-L method. When the following conditions can be satisfied, the indicator can be selected as the final indicator to construct the prosperity index: (1) The difference of time-difference order, which is calculated with the time-difference correlation analysis method and K-L method, is less than or equal to 1; (2) The statistic of time-difference correlation coefficient is greater than 0.5 .

Because of the large number of indicators used for preliminary screening, only adopting time-difference correlation analysis method and K-L method to screen prosperity indicators will lead to too many indicators finally entering the calculation of prosperity index. Therefore, by using the idea of time-difference correlation analysis for reference, this paper puts forward the timedifference grey correlation method to achieve the purpose of screening indicators and improving the quality of indicators. The following mainly introduces timedifference correlation analysis and the calculation method of time-difference grey correlation degree.

\subsection{Time-difference Correlation Analysis}

The basic idea of time-difference correlation analysis method is that, determine the core indicator reflecting the reference cycle at first, then calculate each correlation coefficient between other indicators and the core indicator which is within the leading period and lagging period, finally, according to the correlation coefficient, identify the leading, consistent, or lagging relationship between this indicator and the reference indicator. The calculation method of time-difference correlation analysis is as follows:

Supposing $y=\left\{y_{1}, y_{2}, \ldots, y_{n}\right\}$ is the reference indicator, $x=\left\{x_{1}, x_{2}, \ldots, x_{n}\right\}$ is the selected indicator, the time-difference correlation coefficient $r$ can be defined with Equation (1):

$$
\begin{gathered}
r_{l}=\frac{\sum_{l=1}^{n l}\left(x_{t-l}-\bar{x}\right)\left(y_{t}-\bar{y}\right)}{\sqrt{\sum_{l=1}^{n l}\left(x_{t-l}-\bar{x}\right)^{2} \sum_{l=1}^{n l}\left(y_{t}-\bar{y}\right)^{2}}} \\
t=1,2, \ldots, n ; l=0, \pm 1, \pm 2, \ldots, \pm L
\end{gathered}
$$

where, $l$ represents the leading or lagging period. When $l$ is negative, it means the leading period; when $l$ is positive, it means the lagging period. And $l$ is called time-difference or the delay number. $L$ is the maximum of delay numbers. $n_{l}$ is the number of data after completing missing values. When selecting the prosperity indictors, the time-difference correlation coefficients of several different delay numbers are generally calculated, then their absolute values are compared. The time-difference correlation coefficient with maximum absolute value is $r_{l^{\prime}}$, and it can be formulated as:

$$
r_{l^{\prime}}=\max _{-L \leq l \leq L}\left|r_{l}\right|
$$

The largest time-difference correlation coefficient reflects the time-difference correlation coefficient between the selected indicator and the reference indicator, and the corresponding delay number represents the leading or lagging period.

The correlation coefficient only shows the correlation relationship between the data. Even if the correlation coefficient is close to 1 , it does not mean that there must be a cause-and-effect relationship between the data. So the further analysis is needed to determine the cause-andeffect relationship of time series.

\subsection{Time-difference Grey Correlation Method}

The calculation steps of grey correlation degree without considering the time-difference are as follows.

1. Determine the reference sequence reflecting the characteristics of system behavior and the comparison sequence affecting system behavior.

2. Conduct the dimensionless processing of reference sequence and comparison sequence.

Dimensionless treatment can be carried out for the indicators in the following ways:

$$
\begin{aligned}
& y_{i}^{\prime}=\frac{y_{i}}{M A X\{y\}}, i=1,2, \ldots, n \\
& x_{i}^{\prime}=\frac{x_{i}}{M A X\{x\}}, i=1,2, \ldots, n
\end{aligned}
$$

3. Obtain the grey correlation coefficient between reference sequence and comparison sequence.

The correlation degree is the difference degree of geometry between curves. The correlation coefficient between reference sequence and comparison sequence at each time can be calculated with Equation (5):

$$
\xi_{x y}(i)=\frac{\Delta(\min )+\rho \Delta(\max )}{\Delta_{x y}(i)+\rho \Delta(\max )}
$$

where, $\rho$ is the distinguishing coefficient, and its value is usually $0.5 ; \Delta(\mathrm{min})$ is the minimum difference between two poles, and it can be obtained by making a difference between the reference sequence and the comparison sequence at the corresponding time and taking the minimum absolute difference; $\Delta(\max )$ is the maximum difference between two poles, and it can be obtained by making a difference between the reference sequence and 
the comparison sequence at the corresponding time and taking the maximum absolute difference; $\Delta_{X Y}(i)$ is the absolute difference between each point on the curve of the comparison sequence $Y$ and each point on the curve of the reference sequence $X$.

4. Calculate the correlation degree.

The average value of the correlation coefficient of each time (i.e., each point in the curve) is calculated as the quantitative expression of the correlation degree between the comparison sequence and the reference sequence, the correlation degree $\gamma$ is defined as:

$$
\gamma=\frac{1}{n} \sum_{i=1}^{n} \xi_{x y}(i)
$$

The time-difference grey correlation method proposed in this paper regard the idea of time-difference correlation coefficient as reference, and the grey correlation degree of the reference indicator sequence and the selected indicator sequence is calculated by adjusting the leading or lagging period of the selected indicator sequence (i.e., comparison sequence).

Assuming $l$ represents leading or lagging period. When $l$ is negative, it means leading period; when $l$ is positive, it means lagging period. And $l$ is called timedifference or the delay number. $L$ is the maximum of delay numbers. $n_{l}$ is the number of data. The timedifference grey correlation coefficient can be obtained by Equation (7):

$$
\begin{aligned}
& \xi_{x y_{l}}(i)=\frac{\Delta(\min )+\rho \Delta(\max )}{\Delta_{x y}(i)+\rho \Delta(\max )}, \\
& i=1,2, \ldots, n_{l}, l=0, \pm 1, \pm 2, \ldots, \pm L
\end{aligned}
$$

The correlation degree $\gamma_{l}$ can be expressed as:

$$
\gamma_{l}=\frac{1}{n_{l}} \sum_{i=1}^{n_{l}} \xi_{x y_{l}}(i)
$$

Calculating the time-difference grey correlation degree of different delay numbers, and comparing the absolute values, the time-difference grey correlation degree with the largest absolute value $\gamma_{l^{\prime}}$ can be obtain with Equation (9):

$$
\gamma_{l^{\prime}}=\max _{-L \leq l \leq L}\left|\gamma_{l}\right|
$$

The main difference between time-difference grey correlation method and time-difference correlation analysis is that time difference-correlation analysis focuses on calculating the direction and degree of correlation between two sequences, while time-difference grey correlation method concentrates on calculating the trend consistency of two sequences.

\section{Constructing the power economic prosperity index in Hebei Province}

\subsection{Data Preprocessing}

Data preprocessing is an important prerequisite for constructing the prosperity index, it can reduce the impact of data distortion on the analysis results. The data used in this paper are from the National Bureau of Statistics (http://www.stats.gov.cn/). In order to eliminate the influence of the uncertain factors of the Spring Festival holiday and enhance the comparability of data, according to the national statistical system, most data in January or February are not reported, which could result in data loss. The methods of filling missing data can be mean filling, random filling, regression model filling, weighted adjustment filling and so on. This paper introduces the method of data complement as follows.

Taking the lack of data indicators in January as an example, the general growth rate is used to supplement the data, and the calculating method is:

$$
\begin{gathered}
x_{1}=x_{2} \cdot(1+\alpha) \\
\alpha=x_{3} / x_{2}-1
\end{gathered}
$$

where, $x_{1}, x_{2}$ and $x_{3}$ are the values of indicator $x$ in January, February and March respectively, $\alpha$ is the growth rate.

\subsection{Prosperity Indicators Division}

\subsubsection{The Selection of Reference Indicator}

The reference indicator of power economic prosperity index is the reference of periodic fluctuation of power industry development. In order to ensure the accuracy and comprehensiveness of the analysis results, the selected reference indicator should reflect the periodic fluctuation of power industry as much as possible.

From the existing research, the current reference indicator used in the study of power economic prosperity index mainly include the power generation capacity and the power consumption capacity, and the using frequency of power generation capacity is higher than that of power consumption capacity. The common reference cycle methods generally include classical cycle and growth rate cycle, and the growth rate cycle method is used with a higher frequency. According to the obtained data and reference to the existing literature, this paper selects the year-on-year growth indicator of power generation capacity in Hebei Province as the reference indicator to construct the power economic prosperity index.

\subsubsection{The Preliminary Screening of Prosperity Indicators}

Based on the existing research, the indicators selected in this paper mainly include the following categories:

(1) Price index indicators. Price index is an economic index reflecting the changing direction, trend and degree of the price level of goods and services in different periods. Price index is usually expressed by the relative value of comparison between the reporting period and the base period.

(2) Production indicators. Production indicators are mainly used to reflect the production of upstream and downstream industries related to the power industry, mainly including the production of major energy products and industrial products.

(3) Enterprise economic indicators. Different from the production indicators, the main economic indicators of an 
enterprise refer to the financial indicators of the enterprise, which are mainly used to reflect the operation of the enterprise.

\subsubsection{The Division of Prosperity Indicators}

According to the requirements of index screening, this paper applies time-difference correlation analysis method and K-L method to screen out 17 prosperity indicators that meet the requirements.

Due to the large number of prosperity indicators, the large amount of data in practical application, and the difficulty of data acquisition and sorting, this paper proposes to use time-difference grey correlation degree to further screen prosperity indicators, which can reduce the number of indicators, improve the quality of indicators. The final prosperity indicator system is composed of the indicators whose grey correlation degree is higher than 0.6 . The screening results of power prosperity indicators in Hebei Province are shown in Table 1.

Table 1. The screening results of power prosperity indicators in Hebei Province

\begin{tabular}{|c|c|}
\hline $\begin{array}{l}\text { Indicator } \\
\text { type }\end{array}$ & Indicators \\
\hline \multirow{6}{*}{$\begin{array}{l}\text { Leading } \\
\text { indicators }\end{array}$} & retail price index \\
\hline & $\begin{array}{l}\text { metallurgical sales volume of state-owned } \\
\text { key coal mines }\end{array}$ \\
\hline & $\begin{array}{l}\text { cumulative production of raw iron ore in the } \\
\text { current period }\end{array}$ \\
\hline & $\begin{array}{l}\text { factory gate price index of industrial } \\
\text { producers }\end{array}$ \\
\hline & $\begin{array}{l}\text { cumulative production of liquefied petroleum } \\
\text { gas }\end{array}$ \\
\hline & $\begin{array}{l}\text { total sales volume of state-owned key coal } \\
\text { mines }\end{array}$ \\
\hline \multirow{5}{*}{$\begin{array}{l}\text { Coincident } \\
\text { indicators }\end{array}$} & power generation capacity \\
\hline & thermal power generation capacity \\
\hline & coke production \\
\hline & consumer price index \\
\hline & flat glass production \\
\hline \multirow{6}{*}{$\begin{array}{l}\text { Lagging } \\
\text { indicators }\end{array}$} & wind power generation capacity \\
\hline & $\begin{array}{l}\text { retail price index of transportation and } \\
\text { communication goods }\end{array}$ \\
\hline & $\begin{array}{l}\text { Accumulated amount of real estate } \\
\text { development of completed investment }\end{array}$ \\
\hline & the inventory of state-owned key coal mines \\
\hline & natural gas production \\
\hline & Copper production \\
\hline
\end{tabular}

\subsection{Prosperity Index Construction}

The composite results of electric power prosperity indexes in Hebei Province are shown in Fig. 1.

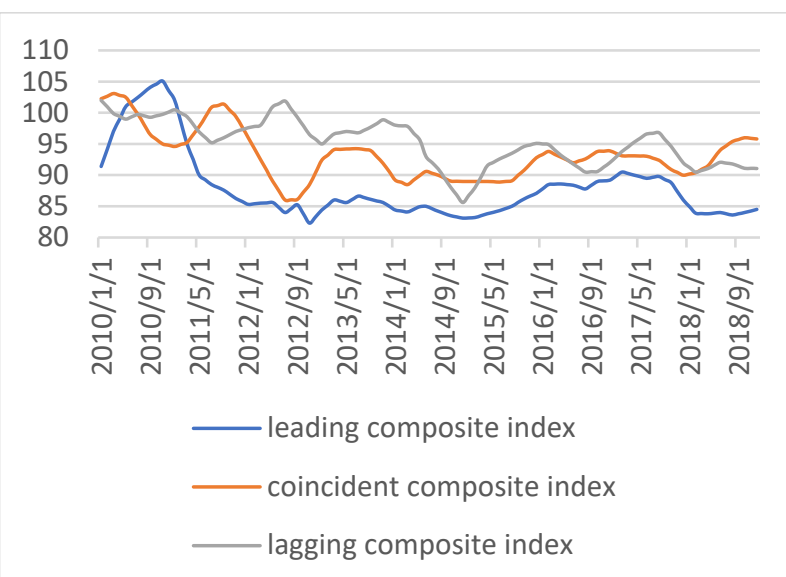

Fig. 1. The power economic prosperity indexes of Hebei Province

From Fig. 1, it can be seen that from 2010 to 2018, the power economic prosperity indexes in Hebei Province can be roughly divided into two stages. The first stage is from 2010 to 2014. In this stage, the power economic prosperity indexes of Hebei Province fluctuated dramatically, and there was a good corresponding relationship among the leading composite index, consistent composite index and lagging composite index. The second stage is from 2015 to 2018. In this stage, the fluctuation of the power economic prosperity indexes of Hebei Province was periodically weakened, and the potential difference among the leading composite index, consistent composite index and lagging composite index was significantly reduced, and the corresponding relationship was not obvious, which brought certain difficulties to the analysis of the power economic prosperity indexes of Hebei Province.

According to the data before 2015, in Hebei Province, the wave peaks of the leading composite index were 10 months and 19 months ahead of the wave peaks of the consistent composite index and lagging composite index respectively; after 2015, the change range of power economic prosperity indexes of Hebei Province decreased, and the operation of power economic prosperity indexes were relatively stable.

From coincident composite index, it can be conducted that the power economic coincident composite index of Hebei Province experienced three relatively complete periodic fluctuations from 2010 to 2018 :

1. The first periodic fluctuation started from January 2011, when the value of consistent prosperity index was 94.6, and then the prosperity index increased obviously, and it peaked with a value of 100.4 in October 2011. After that, the prosperity index dropped sharply, and it reached the bottom in August 2012, with a value of 86.1, which was far lower than the initial valley value of 94.6;

2. The prosperity index of Hebei Province slowly picked up from September 2012, and it reached the second peak in July 2013, with a value of 94.25. Then, it began to decline, and it fluctuated slightly after falling to the bottom in April 2014. After that, the prosperity index was relatively stable, and slowly fell to the bottom in August 2015 , with a value of 89.1 ;

3. From September 2015 to February 2018, although the operation of electric power economic 
prosperity index in Hebei Province fluctuated, it was generally stable, and its value remained between 90 and 95. After March 2018, the power economic prosperity index of Hebei Province picked up again, and the prosperity degree was significantly higher than that in the previous cycle. The period length determined by the peaks and valleys of the consistent composite index is between 30 and 41 months, indicating that the fluctuation period length of the power economic prosperity indexes of Hebei Province is between 2.5 and 3.5 years.

\section{Conclusions}

In this paper, the business cycle analysis method is applied to the power industry, and the prosperity index concerning electric and economic fluctuation of Hebei Province is constructed. The main conclusions of this paper are as follows.

1. It is feasible to apply business cycle analysis to electric power industry. The prosperity index proposed in this paper can reflect the fluctuation state of electric development and economic growth, determine the cycle and turning point of electric power change, and provide the basis for the government and related enterprises to make decisions.

2. Based on the principle of time difference correlation analysis, this paper puts forward the time difference grey correlation degree method, which focuses on the consistency of the two time series in the trend of fluctuation, and can reduce the number of time series to be processed.

3. For Heibei Province, from 2010 to 2018, the electricity-economy fluctuation can be divided into two periods: the first period is from 2010 to 2014, the prosperity index of Hebei province fluctuates violently, and there is a good corresponding relationship among the leading, consistent and lagging composite indexes; the second period is from 2015 to 2018 , the fluctuation of prosperity index of Hebei Province weakened.

\section{References}

1. Akinlo, A. E., Electricity consumption and economic growth in Nigeria: Evidence from cointegration and co-feature analysis. Journal of Policy Modeling, 31, 681-693(2009)

2. Akkemik, K. A.; Goksal, K.; Li, J., Energy consumption and income in Chinese provinces: Heterogeneous panel causality analysis. Appl Energ, 99, 445-454(2012)

3. Asafu-Adijaye, J., The relationship between energy consumption,energy prices and economic growth: Time series evidence fromasian developing countries. Energ Econ , 22, 615-625(2000)

4. Gurgul, H.; Lach, L., The electricity consumption versus economic growth of the Polish economy. Energ Econ , 34, 500-510(2012)

5. Thoma, M., Electrical energy usage over the business cycle. Energ Econ , 26, 463-485(2004)
6. Zhang, C.; Zhou, K. L.; Yang, S. L.; Shao, Z., On electricity consumption and economic growth in China. Renew Sust Energ Rev , 76, 353-368(2017)

7. Gonzalez-Romera, E.; Jaramillo-Moran, M. A.; Carmona-Fernandez, D., Forecasting of the electric energy demand trend and monthly fluctuation with neural networks. Comput Ind Eng , 52, 336343(2007).

8. Lee, Y. S.; Tong, L. I., Forecasting nonlinear time series of energy consumption using a hybrid dynamic model. Appl Energ, 94, 251-256(2012)

9. Liu, C.; Gao, T., Charateristics of electricity industry cycle fluctuation and influential factors of electricity demand based on business analysis and the error correction model Resource Sciences , 33, 169177(2011)

10. Ozturk, I.; Acaravci, A., Electricity consumption and real GDP causality nexus: Evidence from ARDL bounds testing approach for 11 MENA countries. Appl Energ , 88, 2885-2892(2011)

11. Shahbaz, M.; Tang, C. F.; Shahbaz Shabbir, M., Electricity consumption and economic growth nexus in Portugal using cointegration and causality approaches. Energ Policy, 39, 3529-3536(2011)

12. Sun, X.; Zhang, L., Electricity consumption and economic growth causal analysis based on quarterly data. Journal of North China Electric PowerUniversity , 5, 34-38(2015)

13. Tan, Y.; Sun, W., Electric power boom of Shanghai besed on economic analysis. Power System and Clean Energy , 32, 45-50(2016)

14. Vasilev, A., The role of energy in a real-businesscycle model with an endogenous capital utilization rate and a government sector: lessons from Bulgaria (1999-2016). Bulgarian Economic Papers , (5), 223(2018)

15. Li, F.; Luo, X.; Shen, J., Power data-based research on economic prosperity index model. Sichuan Electric Power Technology , 41, 64-68(2018)

16. Zeng, B.; Qin, L. J.; Yan, X.; Lin, X. Q.; Han, S.; Gao, L. K., The establishment and analysis of the prosperity indexes for China's power market. Aer Adv Eng Res , 115, 550-560(2016) 